\title{
Invited review: Use of butyrate to promote gastrointestinal tract development in calves
}

\author{
P. Górka, ${ }^{* 1}$ Z. M. Kowalski, ${ }^{*}$ R. Zabielski, $†$ and P. Guilloteauł \\ *Department of Animal Nutrition and Dietetics, University of Agriculture in Krakow, al. Mickiewicza 24/28, 30-059 Krakow, Poland \\ †Veterinary Research Center, Department of Large Animal Diseases with Clinic, Faculty of Veterinary Medicine, \\ Warsaw University of Life Sciences, ul. Nowoursynowska 100, 02-787 Warsaw, Poland \\ fINRA, Institut National de la Santé et de la Recherche Médicale, Université de Rennes, Université Bretagne Loire, Nutrition, \\ Métabolismes et Cancer, Rennes, 35000, France
}

\section{ABSTRACT}

Promotion of microbial butyrate production in the reticulorumen is a widely used method for enhancing forestomach development in calves. Additional acceleration of gastrointestinal tract (GIT) development, both the forestomach and lower parts of the GIT (e.g., abomasum, intestine, and also pancreas), can be obtained by dietary butyrate supplementation. For this purpose, different sources (e.g., butyrate salts or butyrins), forms (e.g., protected or unprotected), methods (e.g., in liquid feed or solid feed), and periods (e.g., before or after weaning) of butyrate administration can be used. The aim of this paper was to summarize the knowledge in the field of butyrate supplementation in feeds for newborn calves in practical situations, and to suggest directions of future studies. It has been repeatedly shown that supplementation of unprotected salts of butyrate (primarily sodium salt) in milk replacer (MR) stimulates the rumen, small intestine, and pancreas development in calves, with a supplementation level equating to $0.3 \%$ of dry matter being sufficient to exert the desired effect on both GIT development and growth performance. On the other hand, the effect of unprotected butyrins and protected forms of butyrate supplementation in MR has not been extensively investigated, and few studies have documented the effect of butyrate addition into whole milk (WM), with those available focusing mainly on the growth performance of animals. Protected butyrate supplementation at a low level $(0.3 \%$ of protected product in $\mathrm{DM})$ in solid feed was shown to have a potential to enhance GIT development and performance of calves fed MR during the preweaning period. Justification of this form of butyrate supplementation in solid feed when calves are fed WM or after weaning needs to be documented.

Received November 2, 2017.

Accepted January 15, 2018.

${ }^{1}$ Corresponding author: p.gorka@ur.krakow.pl
After weaning, inclusion of unprotected butyrate salts in solid feed was shown to increase solid feed intake, but the effect on GIT development and function has not been determined in detail, and optimal levels of supplementation are also difficult to recommend based on available reports. Future studies should focus on comparing different sources (e.g., salts vs. esters), forms (e.g., protected vs. unprotected), and doses of supplemental butyrate in liquid feeds and solid feeds and their effect not only on the development of rumen, abomasum, and small intestine but also the omasum and large intestine. Furthermore, the most effective source, form, and dose of supplemental butyrate in solid feed depending on the liquid feed program (e.g., MR or $\mathrm{WM}$ ), stage of rearing (e.g., pre- or postweaning), and solid composition (e.g., lack or presence of forage in the diet) need to be determined.

Key words: feed additive, rumen, small intestine, maturation

\section{INTRODUCTION}

The gastrointestinal tract (GIT) of calves is not fully developed at birth. In particular, the forestomach is underdeveloped and not prepared for solid feed digestion (Heinrichs, 2005). Substantial development of the forestomach can be obtained even within the first 3 to 4 wk of postnatal life (Klein et al., 1987; Quigley et al., 1991; Heinrichs, 2005) that results in willing intake and efficient solid feed digestion at a very early age (Hill et al., 2010). However, the development of the forestomach usually proceeds for at least several months (Bailey, 1986; Vazquez-Anon et al., 1993), and the preweaning development may affect the performance and productivity of the animals later on (Khan et al., 2016). Besides the forestomach, in the first weeks of a calf's life, substantial developmental changes are observed in other parts of the GIT, namely the abomasum and small intestine (Guilloteau et al., 2009a; Flaga et al., 2011). These are apparent predominantly in the first 
2 to $3 \mathrm{wk}$ after birth, before the rumen development (Guilloteau et al., 2009a). Furthermore, the first few weeks of a calf's life are a period of extensive pancreatic function development (Biernat et al., 1999; Zabielski et al., 1999; Zabielski et al., 2002). As opposed to the forestomach, the development and maturation of the abomasum, small intestine, and pancreas have an enormous effect not only on solid feed digestion but also on liquid feed digestion [milk or milk replacer (MR)], a main source of nutrients for the newborn calf before the initiation of solid feed intake (Guilloteau et al., 2009b; Górka et al., 2011b).

Because GIT development affects feed intake, efficiency of digestion, and resistance to gastrointestinal disorders, and thus animal growth and health, each method enhancing these processes is highly desirable. In newborn calves, as well as in ruminants in general, promotion of ruminal butyrate production is known to accelerate ruminal epithelium growth and maturation (Sakata and Tamate, 1978; Mentschel et al., 2001). Intraruminal butyrate infusion or intake of feeds high in starch and sugars, which promotes ruminal butyrate production, results in longer ruminal papillae and, likely, a higher surface area for nutrient absorption (Sakata and Tamate, 1978; Mentschel et al., 2001; Lesmeister and Heinrichs, 2005). Therefore, nutritional strategies aiming to stimulate forestomach development in calves are widely used in practice (Heinrichs, 2005; Lesmeister and Heinrichs, 2005; Khan et al., 2016).

It has been shown in numerous studies that substantial acceleration of GIT development in calves can be obtained by dietary butyrate supplementation (Guilloteau et al., 2009b; Górka et al., 2011a,b), as in pig neonates (Kotunia et al., 2004; Le Gall et al., 2009). This effect was not limited to the rumen as butyrate was proved to be an efficient stimulator of the development of abomasum, small intestine, and pancreas in calves (Guilloteau et al., 2009b; Górka et al., 2011a, 2014). Aforementioned reports have been applied in practical nutrition of newborn calves, by proposing commercial feed additives containing butyrate (Hill et al., 2011a,b, 2016). The aim of this paper was to summarize the knowledge in the field of dietary butyrate use to promote GIT development in calves and to suggest directions of future studies.

\section{SOURCES OF BUTYRATE AND ITS IMPORTANCE FOR THE GIT}

Butyrate is short-chain fatty acid (SCFA) and one of the major end products of bacterial carbohydrate fermentation in the forestomach and large intestine (Bergman, 1990). Of the 3 major SCFA produced in the GIT in the largest quantities (acetate, propionate, and butyrate), butyrate is the least abundant but behaves the most dynamically (Ploger et al., 2012). Depending on the diet composition, its molar proportion in total fermentation acids may range from 5 to over $20 \%$ (Ploger et al., 2012). In consequence, its production in the GIT can be modulated to a great extent. Butyrate is also naturally present in milk and dairy products (Guilloteau et al., 2010a) and can be supplemented in feed as butyrate salts (calcium, sodium, potassium, or magnesium) or butyrins (esters of butyrate and glycerol, i.e., mono-, di-, or tributyrin; Moquet et al., 2016). In this paper, to simplify the text, the term "butyrate" will be used interchangeably for acid, anion, salt, and ester forms, and a particular one will be specified and discussed only when necessary. Furthermore, the term "protected" or "unprotected," respectively, will be used for butyrate embedded or not embedded in the continuous lipid matrix, as proposed by Moquet et al. (2016).

\section{Intake with Milk}

Prior to the rumen development, butyrate present in milk is the main source of this molecule for the newborn calf. Although free butyrate concentration in whole milk (WM) is relatively low $(0.16 \mathrm{~g} / \mathrm{L}$ in cow's milk), it may be sufficient to affect GIT development and function (Guilloteau et al., 2010a). Furthermore, in newborn ruminants butyrate is released from milk fat in the abomasum as a result of pregastric lipase action (Drackley, 2008). Bovine milk fat contains 2 to $4 \%$ of butyrate (Palmquist et al., 1993; Chilliard et al., 2009), resulting in overall butyrate content in DM of WM even greater than $1 \%$. As a result, a calf consuming $8 \mathrm{~L}$ of milk/d ( $\approx 1 \mathrm{~kg}$ of DM) consumes up to $10 \mathrm{~g}$ of butyrate/d. In milk fat, butyrate is located at the third position of triacylglycerols, which is a place of pregastric lipase action (Drackley, 2008). Although the amount of butyrate released from milk fat in the abomasum is difficult to assess, it may play an important physiological role (Drackley, 2008; Guilloteau et al., 2010a). To support this hypothesis, butyrate supplemented in MR stimulated the rumen, abomasum, small intestine, and pancreas development in newborn calves (Guilloteau et al., 2009b; Górka et al., 2011b, 2014) and its delivery in $\mathrm{MR}$, even at a very small dose $(0.3 \%$ of $\mathrm{DM})$, was sufficient to modulate GIT secretion of gut regulatory peptides and hormones (Guilloteau et al., 2009b).

\section{Production in the Rumen}

Microbial fermentation of carbohydrates in the rumen is the most important source of butyrate for ruminants (Bergman, 1990). In dairy cows, depending on the stage of lactation and diet composition, its daily 
production may range from 4 up to over $10 \mathrm{~mol}$ and may account for over $10 \%$ of daily SCFA production in the rumen (Dieho et al., 2016). Up to $90 \%$ of ruminal butyrate is absorbed directly from the rumen (Bergman, 1990) and most of this pool is metabolized by the ruminal epithelium (Bergman, 1990; Kristensen et al., 2000a; Kristensen and Harmon, 2004a). Butyrate has also been shown to inhibit acetate and propionate activation and metabolism in vitro (Ash and Baird, 1973; Harmon et al., 1991), and its supplementation in the diet decreased glucose oxidation by the ruminal epithelia preparations (Wiese et al., 2013). As a result, butyrate is considered as an important energy source for the ruminal epithelial cells (Bergman, 1990), although it is metabolized by the ruminal epithelium mostly to ketone bodies (BHB and acetoacetate; Weigand et al., 1972; Kristensen et al., 2000b) that does not result in a relevant amount of ATP formation (Kristensen and Harmon, 2004b).

Besides serving as an energy substrate, butyrate is an important stimulator and regulator of the ruminal epithelium growth and function (Penner et al., 2011). In preruminant calves, infusion of butyrate directly into the lumen of the developing rumen stimulated ruminal epithelial cells proliferation and reduced their apoptosis (Sakata and Tamate, 1978; Mentschel et al., 2001). This resulted in longer rumen papillae (Mentschel et al., 2001) and, in consequence, most likely a larger surface area for nutrient absorption, as shown in growing but already ruminating or mature ruminants (Shen et al., 2005; Malhi et al., 2013). The stimulatory effect of butyrate on the ruminal epithelium growth has been known for years and promotion of its formation in the rumen, by feeding diets high in starch and sugars, is widely used as a means of speeding up forestomach development in calves (Heinrichs, 2005; Lesmeister and Heinrichs, 2005). Butyrate is also known to affect metabolic activity of the ruminal epithelium (Harmon, 1986; Wiese et al., 2013), abundance of transcript of proteins mediating SCFA absorption (Malhi et al., 2013; Dengler et al., 2015), epithelial blood flow (Storm et al., 2011), and rumen motility (Kendall and McLeay, 1996). When infused directly into the rumen, butyrate increased efficiency of SCFA absorption from the rumen in growing goats (Malhi et al., 2013) and total nutrient digestibility in dairy cows (Huhtanen et al., 1993). In cows, butyrate infusion into the rumen resulted in the expansion of one of the most abundant rumen bacteria phyla (Firmicutes) and stimulated the population of butyrate-producing bacteria ( $\mathrm{Li}$ et al., 2012a). It is believed that butyrate exerts a similar effect on the efficiency of nutrient digestion, absorption, and GIT microflora in newborn ruminants, but unambiguous evidence is lacking.
Besides the direct effect on the rumen, ruminal butyrate may affect the omasum, abomasum, and small intestine. Butyrate infusion into the rumen increased the amount of butyrate entering the duodenum (Górka et al., 2017a), and when infused into the abomasum, it affected the expression of various genes in the duodenal epithelium (Foote et al., 2017). In general, little is known about the role of microbial butyrate released in the rumen and entering the omasum, abomasum, and then the proximal small intestine on the structure and functions of those parts of the GIT. Some information on the effect of butyrate on abomasal mucosa can be extrapolated from studies in simple-stomached species. Accordingly, Kotunia et al. (2004) and Mazzoni et al. (2008) demonstrated the trophic effect of butyrate supplementation on the stomach mucosa and muscularis in neonatal piglets, and Andoh et al. (1999) showed the anti-inflammatory effect on gastric mucosal cells in adult rats; however, possible species differences have to be taken into account.

\section{Fermentation in Lower Parts of the GIT}

Similarly to monogastric animals, butyrate is produced in the distal small intestine and large intestine in ruminants (Bergman, 1990). Its concentration in the digesta of the large intestine can be similar to that found in the rumen fluid, at least in adult ruminants (Li et al., 2012b). Although the importance of butyrate for the functions of the large intestine in ruminants has not been extensively investigated, it is believed to be similar to that known for monogastric species. To support this, a substantial amount of work is needed with suitable animal models.

\section{DIETARY SUPPLEMENTATION OF BUTYRATE}

In the first 1 to 2 wk of a calf's life, solid feed intake is very low and rumen microflora is not fully developed. This results in a very low butyrate concentration in the yet underdeveloped rumen until regular solid feed intake starts and rumen microflora develops (Anderson et al., 1987; Flaga et al., 2015). Furthermore, due to economic considerations, MR are often used in the diets for newborn calves, instead of WM. The former is known to delay the development of the GIT, mostly due to a lack of milk-borne bioactive components and the presence of antinutritional factors of plant origin in the calf MR (Seegraber and Morrill, 1986; Zabielski, 1998; Górka et al., 2011b). Additionally, in contrast to WM, in most cases MR contain no milk fat but plant (palm oil, coconut oil) or animal (lard, tallow) alternatives that are unlikely to contain the amount of butyrate required for the calf. This altogether encourages dietary 
butyrate supplementation in the diet for newborn ruminants as a means of promoting GIT development. Nowadays, therefore, many calf MR available on the market are enriched with butyrate.

\section{Sources and Forms of Dietary Butyrate}

Butyrate can be supplemented as salts or butyrins. The main advantages of using these sources of butyrate over free butyric acid is that they are more stable, less odorous and easier to handle in feed manufacturing processes (Guilloteau et al., 2010a). However, the diverse sources of butyrate have different physical and chemical properties. Sodium butyrate, the most often used source of dietary butyrate due to its high availability and modest price, dissolves easily in water and rapidly dissociates in water solutions (Mallo et al., 2012). As a result, dietary sodium butyrate rapidly dissociates in the stomach (forestomach, abomasum) and is most likely completely absorbed in those parts of the GIT (Guilloteau et al., 2009b). On the other hand, calcium butyrate is much less soluble in water solutions compared with sodium butyrate (Mallo et al., 2012). Therefore, it can be expected that at least part of the butyrate delivered as calcium butyrate can reach the small intestine. Other salts (potassium, magnesium) are currently not used as sources of butyrate in animal nutrition. In turn, when delivered as mono-, di-, or tributyrin, butyrate must be released from glycerol before it elicits its effect on the GIT. Due to pregastric lipase activity in newborn ruminants, at least a portion of the butyrate (particularly when supplemented in liquid feed) is expected to be cleaved from glycerol in the abomasum; however, most of this molecule is supposed to be released in the proximal small intestine, and only trace amounts, if any, are expected to reach the distal small intestine and large intestine (Moquet et al., 2016). It is also worth mentioning that pregastric and pancreatic lipase cleave ester bonds of triacylglycerols at the first and third position (Doreau and Chilliard, 1997). Consequently, at least part of the butyrate provided as di- and tributyrin is absorbed from the GIT as sn-2 monobutyrin (Moquet et al., 2016).

The effect of dietary butyrate supplementation can be modulated by butyrate protection from its release and utilization in the stomach (both forestomach and abomasum). Embedding in the continuous lipid matrix, often referred as microencapsulation or fat coating, is commonly used for this purpose (Claus et al., 2007; Górka et al., 2011a, 2014; Moquet et al., 2016). Vegetable saturated fats such as palm oil fractions are the most often used embedding material; however, the exact composition of the lipid matrix is rarely reported (Mo- quet et al., 2016). When supplemented in unprotected form, butyrate is rapidly taken up by the epithelial cells of the proximal section of the GIT (the forestomach, stomach, or proximal small intestine, depending on method and source of delivery) and cannot be detected in the blood and digesta of the proximal small intestine (Manzanilla et al., 2006; Guilloteau et al., 2009b). On the other hand, when protected in the lipid matrix, butyrate is only partially released in the stomach as a result of its washout from the surface of the microcapsules and microbial (forestomach) and pregastric (abomasum) lipase action. Most of active substance is gradually released in the small intestine, where the highest and the complementarities of lipolytic activities are present due to the gastric, pancreatic, and intestinal enzyme production (Piva et al., 2007; Guilloteau et al., 2009a). The remaining portion, not released in the stomach and small intestine, can be subjected to microbial action in the large intestine and released in this section of the GIT. Unfortunately, an exact location of active substance release along the GIT for most commercial protected products is not provided (Moquet et al., 2016), although targeting the location of release is defined (e.g., mostly the small intestine or mostly the large intestine). This, however, may be affected by the age of the animal, GIT development and feed composition, as well as embedding material composition (length of fatty acid chain, degree of saturation of the lipid matrix), extra coating, granule size/volume ratio, and also the interactions between all those mentioned above.

\section{Methods of Supplementation}

Taking into account that in preruminants solid feed enters the rumen whereas liquid feed (milk or MR) bypasses it via the esophageal groove and enters the abomasum and then small intestine, butyrate supplementation in solid feed or liquid feed or in both can be considered (Figure 1; Górka et al., 2011a). When supplemented in solid feed, butyrate is expected to predominantly affect the forestomach (rumen), whereas the effects of its addition into the liquid feed can be expected mostly in the abomasum and small intestine. Additionally, a positive effect of butyrate addition into the liquid feed on abomasum and small intestine development and associated enhanced digestibility could result in higher solid feed intake and thus, in turn, could affect forestomach development (Górka et al., 2011b). By contrast, faster forestomach development and associated higher solid feed intake when butyrate is supplemented in the solid feed may indirectly affect lower GIT parts due to the known effect of not only 


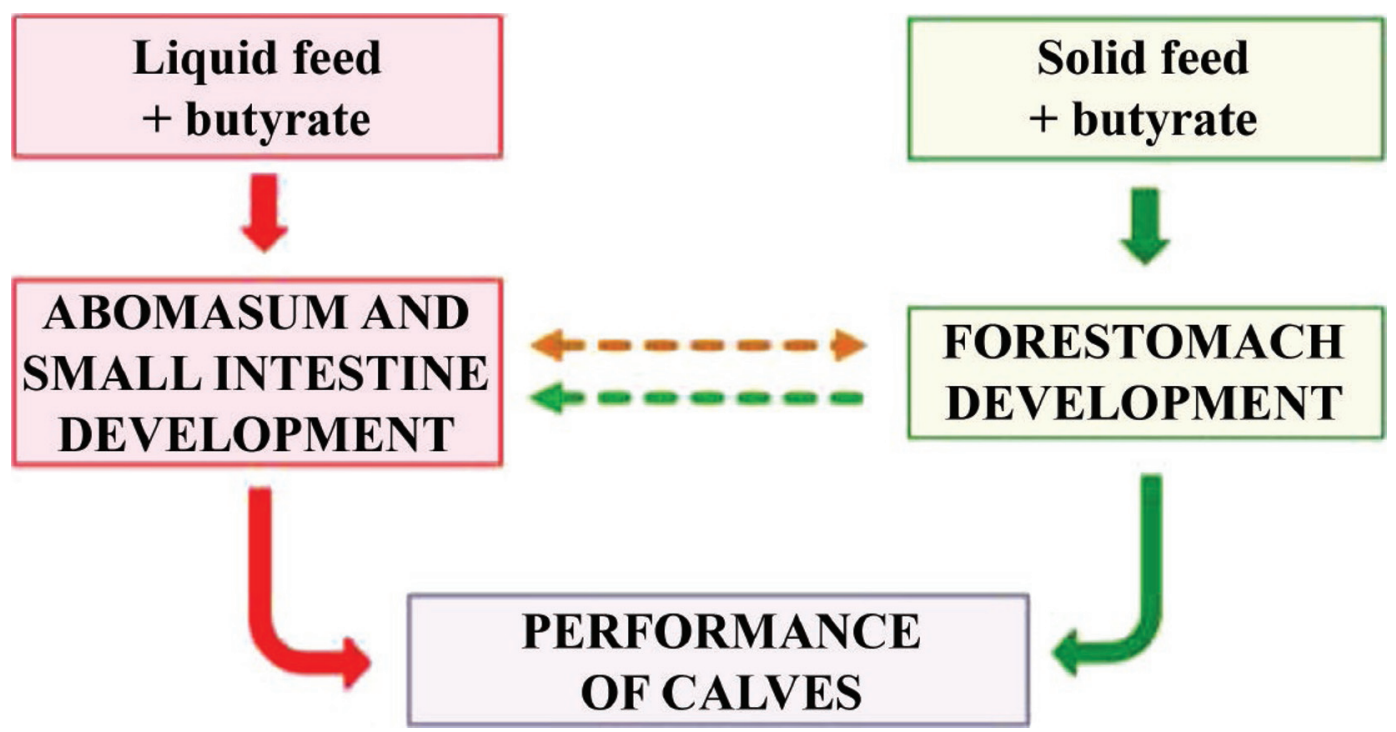

Figure 1. The effects of dietary butyrate on gastrointestinal tract (GIT) development in calves. The gray/brown dotted line indicates the possible indirect effect of butyrate supplementation in liquid feed on forestomach development and in solid feed on abomasum and small intestine development. The black/green dotted line indicates the possible direct effect of butyrate supplementation in solid feed on the abomasum and small intestine due to incomplete butyrate utilization in the stomach (forestomach and abomasum) and its flow with digesta to the lower parts of the GIT, particularly when protected forms of butyrate are used in solid feed. Color version available online.

liquid feeds but also solid feeds on the structure and function of the lower GIT in newborn ruminants (Guilloteau et al., 2009b). Therefore, butyrate addition into both liquid and solid feed could be recommended for young calves (Górka et al., 2011a, 2014).

\section{EFFECT OF SUPPLEMENTATION IN LIQUID FEED}

So far only the effect of unprotected forms of butyrate supplementation in liquid feed on GIT development in calves has been investigated. Only one study documents the effect of protected butyrate supplementation in MR (Nazari et al., 2012), but in this study mainly the growth performance of calves was investigated and a very limited number of animals was used, making the results of low value. Furthermore, in most of studies conducted so far, butyrate has been supplemented in MR, with only one study focusing on its addition into the WM. The animals in this study were supplemented only for $23 \mathrm{~d}$ and mostly growth performance and feed intake were controlled (Davarmanesh et al., 2015). As already mentioned, butyrate is present in the WM (Palmquist et al., 1993; Chilliard et al., 2009; Guilloteau et al., 2010a), but its content in MR is lacking, or nearly lacking. Therefore, butyrate supplementation in MR is especially justified (Guilloteau et al., 2009b; Górka et al., 2011b). However, it cannot be excluded that fortification of WM with butyrate could also affect GIT development and enhance the performance of calves.
Compared with unsupplemented control, unprotected butyrate supplementation in calf MR has been shown to predominantly affect small intestine and pancreas development and function. It increased mitotic and decreased apoptotic index in the jejunal epithelium (Guilloteau et al., 2009b; Górka et al., 2011b), and longer intestinal villi and thicker tunica mucosa were observed in the duodenum, and proximal and distal jejunum, but not in the middle jejunum (Guilloteau et al., 2009b). It is worth mentioning that the mitosisto-apoptosis ratio in the intestinal epithelium of calves fed MR with supplemental butyrate was comparable to that observed in calves fed WM (Górka et al., 2011b). Butyrate addition into MR also increased the activity of main brush border enzymes (Guilloteau et al., 2009b; Górka et al., 2011b, 2014) and the secretion of pancreatic juice as well as chymotrypsin and lipase (Guilloteau et al., 2010b). Circadian pancreatic juice secretion was also modulated. Specifically, in supplemented animals pancreatic juice secretion was higher $3 \mathrm{~h}$ after MR feeding, meaning that this secretion was enhanced when the digesta arrival into the small intestine is at its highest (Guilloteau et al., 2010b). Greater serum amylase and lower serum urea was also reported when unprotected butyrate was supplemented in MR, suggesting greater pancreatic secretion and more efficient AA use in supplemented animals (Hill et al., 2007a). Moreover, butyrate supplementation increased heat shock protein (HSP27 and HSP70) expression in the abomasal and large intestinal mucosa (Guilloteau 
et al., 2009b), indicating that it exerts a cytoprotective effect on the mucosa of those parts of the GIT. Besides the effects already mentioned, butyrate enhanced ruminal epithelium development (Górka et al., 2011b; Kato et al., 2011). In terms of growth performance, butyrate use in MR increased average daily weight gain of animals in many (Hill et al., 2007b; Guilloteau et al., 2009b; Górka et al., 2011a, 2014) but not all studies (Kato et al., 2011; Araujo et al., 2015; Frieten et al., 2017). Butyrate supplementation in MR also reduced the probability of diarrhea in calves (Hill et al., 2007b; Górka et al., 2011a). When combined with medium-chain fatty acids (e.g., caprylic, capric, lauric, and myristic) and PUFA (e.g., linolenic), butyrate had a positive effect on growth performance and efficiency of nutrient digestion, and altered immune response of calves (Hill et al., 2011a,b, 2016). Taken together, unprotected butyrate addition into MR is expected to translate into more efficient nutrient digestion as well as better growing and healthier animals, and those expectations have been confirmed in many studies.

Among the available unprotected forms, sodium butyrate has been the most often used source of butyrate in MR, at least in studies published in peer-reviewed journals (Hill et al., 2007b; Guilloteau et al., 2009b; Górka et al., 2011b; Kato et al., 2011). So far, an attempt to compare different sources of unprotected butyrate use in MR has been made in only one study (e.g., sodium butyrate and tributyrin; Araujo et al., 2015). In this study, tributyrin supplementation negatively affected the feed intake and growth performance of calves, whereas sodium butyrate supplementation had no effect. The results of this study proved that the source of dietary butyrate may determine the final results of its supplementation. Because sodium butyrate supplemented in MR should rapidly dissociate and be rapidly utilized at the stomach level (Manzanilla et al., 2006; Guilloteau et al., 2009b), whereas at least a portion of butyrate delivered as tributyrin should flow with digesta to the duodenum (Moquet et al., 2016), the results of the aforementioned study may also suggest that forms of butyrate easily available at the abomasum level may be superior to those ensuring only limited release of butyrate in this part of the GIT (butyrins) or protected forms of butyrate. One cannot exclude possible effects of glycerol from tributyrin on the intestine as well. Nevertheless, no strong scientific evidence is currently available to support the above statement.

Despite a clear lack of evidence as to the advantages of protected forms of butyrate use in MR on GIT development and the performance of calves, protected forms of butyrate are used in commercial MR. Although limited, some reports seem to suggest that such a practice may be justified, at least in terms of the growth performance of animals (Chester-Jones et al., 2012; Nazari et al., 2012). Of potential advantage, protected butyrate is released slowly from the lipid coat, providing the possibility for its more uniform distribution in the small and large intestine. Therefore, protected butyrate is more likely to affect the structure and function of the large intestine due to butyrate delivery to the very last sections of the intestine. This seems to be especially beneficial taking into account the high susceptibility of newborn calves to diarrhea. Independent of the reason of diarrhea, the large intestinal function is at least indirectly affected. However, unprotected butyrate supplementation in MR was shown to affect also the large intestine, as indicated by higher heat shock protein expression in the large intestine epithelium in the supplemented animals (Guilloteau et al., 2009b). It seems that some indirect effects occurring thanks to improved digestive function in the upper gut may play a role.

Well-designed studies with an appropriate number of animals are necessary to document and justify protected forms of butyrate use in MR for newborn calves. Future studies should also focus on comparing different sources (e.g., salts vs. esters) and forms (e.g., protected vs. unprotected) of supplemental butyrate in MR on GIT development and growth performance of calves. Moreover, so far only one report is available that presents the effects of butyrate supplementation in WM. When calcium butyrate was used in WM, no effect on the performance of calves was detected during the preweaning stage of rearing, as opposed to supplementation in solid feed after weaning (Davarmanesh et al., 2015). This lack of effect may be explained by the presence of butyrate in WM. Alternatively, due to the perfect composition of WM containing a waste number of biologically active substances and highly digestible proteins and lipids, no further increase in parameters above the optimal could be observed. However, the effects of different sources and forms of butyrate supplementation in the WM on calf GIT development cannot be currently excluded, and may differ substantially from their effects of supplementation in MR.

\section{EFFECT OF SUPPLEMENTATION IN SOLID FEED}

The effects of both protected and unprotected butyrate supplementation in solid feed for newborn ruminants on GIT development and growth performance have been extensively investigated (Ślusarczyk et al., 2010; Górka et al., 2011a, 2014; Cavini et al., 2015). To date, however, a direct comparison of those 2 forms of butyrate addition into solid feed for calves is lacking. 


\section{Effect of Unprotected Butyrate Use}

Due to rapid dissociation of unprotected butyrate in water solutions (Mallo et al., 2012), particularly sodium salt, the supplementation of such sources of butyrate in solid feed is expected to predominantly affect the rumen. In line with this hypothesis, unprotected butyrate use in concentrates increased the rumen papillae length, concentrate intake, and ADG of lambs. However, reticulorumen mass was lower in the supplemented animals compared with the control (Cavini et al., 2015). Furthermore, the aforementioned effect on GIT development and the performance of lambs was observed only during the preweaning phase of rearing. On the other hand, unprotected butyrate supplementation in concentrate for calves increased solid feed intake mainly after weaning, but only a trend to greater average daily weight gain was observed (Ślusarczyk et al., 2010). Greater solid feed intake in supplemented calves suggests more advanced rumen development. Whether this was a result of butyrate action during the preweaning phase of growth that translated into greater solid feed intake after weaning, or whether unprotected butyrate affects rumen development mainly after weaning remains to be resolved. Such knowledge could allow for better optimization of unprotected butyrate use in solid feed by its inclusion in the diet in a period of its most apparent action, which could also limit any potential negative consequences of its intake in the diet, as discussed below.

Although the stimulatory effect of butyrate supplementation in solid feed may affect lower parts of the GIT, as already discussed, such an effect has not been documented in detail in newborn calves, and newborn ruminants in general. It is also worth mentioning that currently only studies presenting the effect of unprotected butyrate salt use in solid feed on GIT development and the performance of ruminants are available in the literature, whereas no reports on butyrin supplementation can be found.

\section{Effect of Protected Butyrate Use}

At least in the first weeks of a calf's life, most of the butyrate supplemented in a protected form is expected to bypass the forestomach and abomasum and be delivered to the small intestine, where it exerts a local effect on the intestinal epithelium. The potential advantage of this form of butyrate use in solid feed is also slower and more sustained butyrate release in the rumen (Górka et al., 2011a; Kowalski et al., 2015). Indeed, protected butyrate supplementation in the starter diet for calves has been reported to enhance both forestomach and small intestine development. Higher reticulorumen mass, longer rumen papillae, and higher small intestine mass were observed in the animals fed a supplemented starter diet (Górka et al., 2011a, 2014). This method and form of butyrate delivery affected the mitotic and apoptotic index of the small intestinal epithelium, its architecture, and brush border enzyme activity (Górka et al., 2014).

Hydrogenated fats, commonly used as an embedding matrix in protected products, can be an effective method of active substance delivery to the lower parts of the GIT in ruminants (Wu and Papas, 1997; Rossi et al., 2003). Additionally, symbiotic microflora in the rumen is not fully developed in the first weeks of life which may further limit butyrate release from the lipid matrix in this region of the GIT. Butyrate embedded in small fat microcapsules (size usually less than $1 \mathrm{~mm}$ ) may be also readily transported via the reticulo-omasal orifice. Taken altogether, this may explain the effect of protected butyrate in solid feed not only on the rumen, but also on the small intestine. Nevertheless, the efficiency of butyrate protection from its release in the rumen of a newborn has not been shown so far in a wellcontrolled study, and may depend on the composition of the embedding matrix, age of the animals, starter feed intake, and so on.

To date, a positive effect of protected butyrate use in solid feed on GIT development and growth performance has been shown in newborn calves only during the preweaning period (Górka et al., 2011a, 2014; Serbester et al., 2014). The preliminary results of our group suggest that protected butyrate has the potential to enhance GIT development and solid feed intake during the preweaning period, and that this effect is much smaller or even diminishes after weaning, even though a potential positive effect on some parameters of GIT function was still observed, such as greater activity of brush border enzymes (Burakowska et al., 2017). Calves fed a starter mixture with protected butyrate also had a lower absorptive surface area in the ventral sac of the rumen 3 wk after weaning, as compared with the control (Burakowska et al., 2017). As a result, there is currently no justification for including protected forms of butyrate in solid feed after weaning, and no evidence that the benefits of its supplementation preweaning translate into the later stages of rearing.

The different results obtained according to either lack of butyrate protection or protection with lipid matrix, particularly after weaning, can be explained by the different availability of the butyrate to ruminal microorganisms. It can be speculated that butyrate supplementation in a nonprotected form results in short-lasting prandial elevation of butyrate in ruminal fluid that can be harvested by the microorganisms, and little butyrate will remain for the ruminal tissues, at least when 
butyrate supplementation at low level is considered. In contrast, protection potentially warrants less sharp and longer lasting elevation of ruminal butyrate, which can be potentially better utilized by the ruminal tissues (Górka et al., 2011a; Kowalski et al., 2015). As such, protection of butyrate should improve the exposition of butyrate to the ruminal epithelium and thereby improve its absorption (gradient- or receptor-driven, or both) to epithelial cells and utilization. Nevertheless, what has been shown to be of use in adult ruminants (Kowalski et al., 2015) is not necessarily true for weaned calves (Burakowska et al., 2017). More research is required to determine the advantages and disadvantages of protected butyrate supplementation in the starter mixtures for calves, with particular emphasis on the expected differences of its supplementation between pre- and postweaning periods.

\section{EFFECT OF BUTYRATE SUPPLEMENTATION IN LIQUID AND SOLID FEED}

Although butyrate supplementation in both MR and solid feed affects GIT development in young ruminants, no synergistic effects of butyrate addition into both MR and solid feed on GIT development and the performance of newborn calves have been shown (Górka et al., 2011a, 2014). Nevertheless, unprotected butyrate addition into $\mathrm{MR}$ reduced $\mathrm{BW}$ loss in calves transitioned to $\mathrm{MR}$, whereas protected butyrate addition in the starter diet increased starter diet intake. Consequently, butyrate supplementation in both MR (unprotected form) and starter (protected form) for newborn calves can be recommended, at least in the first month of postnatal life (Górka et al., 2011a, 2014).

\section{MECHANISMS OF BUTYRATE ACTION}

\section{Supplementation in Liquid Feed}

Butyrate present in milk or MR or released in the GIT during milk fat digestion may affect GIT development and function directly by serving as an energy source for the GIT tissues (Drackley, 2008; Guilloteau et al., 2010a), or indirectly via the effect on the secretion of GIT peptides and hormones or vagal nerve stimulation (Guilloteau et al., 2010a). Of those 2 potential mechanisms of butyrate action, the latter one (indirect effect) seems to be more relevant (Guilloteau et al., 2009b, 2010a). This hypothesis is based on the generally low butyrate presence in milk and proven butyrate effect on GIT development when supplemented in MR at a very low level (Guilloteau et al., 2009b; Górka et al., 2011b), which is unlikely to provide a relevant amount of energy for the GIT tissues. Furthermore, delivery in an unprotected form results is complete butyrate release, absorption, and metabolism at the stomach level, as it cannot be found in the blood and digesta of the proximal small intestine (Manzanilla et al., 2006; Guilloteau et al., 2009b).

An indirect effect is most likely induced by butyrate effect on gut regulatory peptides secretion by the stomach and proximal intestine, or stimulation of the vagal nerve, or both (Guilloteau et al., 2009b, 2010b). However, the results of studies conducted to date have so far failed to determine the exact indirect mechanism behind the butyrate action. For example, sodium butyrate supplementation in MR had no effect or reduced blood concentrations of the investigated gastrointestinal peptides, having a trophic effect on the GIT tissue growth (e.g., gastrin or cholecystokinin; Guilloteau et al., 2009b, 2010b). Furthermore, postprandial plasma insulin and growth hormone levels were lower in calves fed MR with supplemental butyrate (Kato et al., 2011). Nevertheless, it is well known that a neurohormonal stimulation on gut tissue level may not be reflected in elevated concentrations of gut regulatory peptides in the peripheral blood (e.g., the external jugular vein; Zabielski et al., 1994; Konturek et al., 2003). To support the indirect mode of butyrate action, and particularly stomach-derived mechanism, sodium butyrate infusion into the duodenum had a minor effect on the pancreas function compared with its delivery in MR (Guilloteau et al., 2010b) that most likely resulted in butyrate absorption and metabolism before entering the duodenum. Vagally driven mechanisms that control the upper gastrointestinal tract, including the pancreas and duodenum, function from birth in neonatal calves (Biernat et al., 1999; Zabielski et al., 2002). On the other hand, enhanced small intestine and pancreas development that result in more efficient digestibility of nutrients at least partially explains faster ruminal epithelium development in calves fed MR with supplemental butyrate (Górka et al., 2011b; Kato et al., 2011), simply due to the higher availability of nutrients for the developing rumen arriving from the circulation. An explanation of the effects of the exact mechanism of butyrate on GIT development in calves when this molecule is delivered in liquid feed remains to be clarified.

\section{Supplementation in Solid Feed}

Because butyrate is considered as an important energy source for the ruminal epithelial cells (Bergman, 1990; Wiese et al., 2013), unprotected butyrate supplementation in solid feed results in the provision of easily available energy substrate for the growing tissue. 
Besides that, it is believed that butyrate stimulates ruminal epithelial cells proliferation also indirectly, via its effect on hormones and growth factors secretion such as IGF-1 or insulin (Baldwin et al., 2004; Penner et al., 2011). This effect can be both endocrine and paracrine (Shen et al., 2012; Steele et al., 2012; Herrick et al., 2017). Taking into account that even a very low level of butyrate supplementation affects rumen epithelium development and feed intake in newborn ruminants (e.g., 0.3\% of DM; Ślusarczyk et al., 2010; Cavini et al., 2015), its effect on ruminal epithelium growth and maturation may be even more dependent on the aforementioned indirect modes of action than the provision of energy for proliferating cells. It has also been shown that ruminal butyrate (and SCFA in general) increase induces epithelium inflammation, and that this may lead to increased ruminal epithelial cells repair as well as their proliferation (Connor et al., 2013). It is also worth mentioning that a rapid but short-in-duration increase in ruminal butyrate, expected when its unprotected forms are supplemented in solid feed, was shown to be a more potent stimulator of ruminal epithelial cells proliferation than increased but sustained ruminal butyrate availability (Sakata and Tamate, 1978). This may explain the possibly more efficient use of unprotected compared with protected butyrate after weaning and the necessity of higher dosage use to affect ruminal butyrate availability when its production in the rumen may be already quite large (see discussion below). The effect on rumen microbes has been discussed previously (see "Sources of Butyrate and Its Importance for the GIT").

When supplemented in protected form, butyrate supplementation in the starter diet was shown to increase plasma glucagon-like peptide-2 (GLP-2) in the first 2 wk of a calf's life. The GLP-2 is secreted by L-endocrine cells in the small and large intestine, notably in the ileum and colon (Drucker, 2002) and is a well-known stimulator and regulator of GIT development and function in mammals, particularly the small intestine (Burrin et al., 2003). This effect of protected butyrate use, besides proving that at last partially protected butyrate bypasses the rumen and enters and is released in the intestine, translated into faster small intestine development and maturation. This, in turn, could be to some extent responsible for more willing solid feed intake observed in calves fed a starter diet supplemented with microencapsulated butyrate (Górka et al., 2011a; Burakowska et al., 2017). The combined, faster rumen development in calves fed a starter diet with protected butyrate, besides the direct effect of butyrate on rumen development, may be a result of its indirect effect via the stimulation of small intestine development.

\section{Effects Independent of Method of Supplementation}

Independent of method of supplementation, butyrate affects histone acetylation and, in consequence, may affect GIT development and function by affecting gene expression (Guilloteau et al., 2010a; Canani et al., 2011). Moreover, in monogastric species dietary butyrate prevented colonization of GIT by harmful or potentially harmful pathogens (Galfi and Bokori, 1990; Fernández-Rubio et al., 2009). Whether its effect on GIT microbiota is direct or indirect (by affecting the overall health of the animal) is still under discussion (Moquet et al., 2016); however, dietary butyrate supplementation in MR was shown to also decrease the probability of digestive upsets in calves (Hill et al., 2007b; Górka et al., 2011a), and its possible antimicrobial action has been widely discussed (Drackley, 2008; Guilloteau et al., 2010a) also for humans (Krokowicz et al., 2014). The latter reference gives an elegant example of reducing symptoms of travelers' diarrhea caused by an undefined pathogenic and conditionally pathogenic microbials, and supports the argument that dietary butyrate use prevents diarrhea.

\section{RECOMMENDED BUTYRATE SUPPLEMENTATION}

\section{Factors Influencing the Optimal Form and Dose}

At least several factors should be taken into account when discussing the optimal source (e.g., salts or butyrins), form (e.g., protected or unprotected) and dose of butyrate supplementation, such as the age of animals, lack or presence of liquid feed in the diet, amount and type of solid feed intake, and the proportion of concentrate in the diet. All of these factors may affect the results of dietary butyrate use. In the majority of cases, more detailed studies are required for precise recommendations. Nevertheless, studies on preruminant calves and newborn piglets suggest that butyrate supplementation should be initiated as early as possible after birth for the most apparent effects (Kotunia et al., 2004; Guilloteau et al., 2009b; Le Gall et al., 2009; Górka et al., 2011b), and that supplementation in early postnatal life may translate into the later stages of life (Le Gall et al., 2009). No evidence is currently available that this recommendation should be different for protected or unprotected forms of butyrate or their different sources. On the other hand, unprotected butyrate supplementation in solid feeds for calves has been shown to increase feed intake mainly after weaning (Ślusarczyk et al., 2010), as opposed to the effect of protected forms, most apparent before weaning (Górka et al., 2011a; Serbester et al., 2014; Burakowska et 
al., 2017). However, to date the investigated levels of unprotected forms of butyrate used in solid feed for newborn calves have been higher than the levels used for protected forms (Ślusarczyk et al., 2010; Górka et al., 2011a; see discussion below), suggesting that the optimal level of supplementation in solid feed may differ before and after weaning. Furthermore, a high level of supplementation $(\approx 3 \%$ in the dietary $\mathrm{DM})$ in solid feed may not be recommended when a high concentrate diet is fed (Ślusarczyk et al., 2010) that already ensures high butyrate production in the rumen. In consequence, the feed composition and forage-to-concentrate ratio, or a combination of these 2 , may be a very important factor determining the efficiency of dietary butyrate supplementation, particularly around weaning time when solid feed intake rapidly increases (Hill et al., 2010; Khan et al., 2016).

\section{Recommended Doses}

In general, the recommended levels of supplemental butyrate in feeds for calves are low or very low. Unprotected butyrate use in MR at the level of $0.3 \%$ of DM is the most often recommended because it was sufficient to exert a stimulatory effect on the GIT development and function and to improve growth performance (Guilloteau et al., 2009b; Górka et al., 2011a; Table 1). However, even up to 3 times greater levels of supplementation were also well tolerated by calves (Hill et al., 2007b; Kato et al., 2011). Such a dose of butyrate also corresponds with its content and potential intake with WM (Palmquist et al., 1993; Chilliard et al., 2009). When used in solid feed, positive effects of unprotected butyrate on GIT development (that translated into better performance of animals) were shown, with supplemental doses ranging from 0.3 to over 1\% of DM (Ślusarczyk et al., 2010; Ferreira and Bittar, 2011; Cavini et al., 2015; Table 2). A lower level of supplementation $(0.3 \%$ of $\mathrm{DM})$ was shown to have a positive effect on GIT development, feed intake, and growth performance in lambs during the preweaning period, but was insufficient to sustain such an effect after weaning (Cavini et al., 2015). On the other hand, unprotected butyrate supplementation in concentrate at the level of 0.3 and 1\% (as fed) increased solid feed intake in calves mostly after weaning (Ślusarczyk et al., 2010). An inclusion rate equating to $3 \%$ of concentrate had no positive effect on feed intake and ADG (Ślusarczyk et al., 2010).

As compared with the unprotected form, recommended doses of protected butyrate supplementation in solid feed are very low. Microencapsulated product use in starter diet at a level of $0.3 \%$, which equates in most cases to less than $0.1 \%$ of supplemental butyrate,

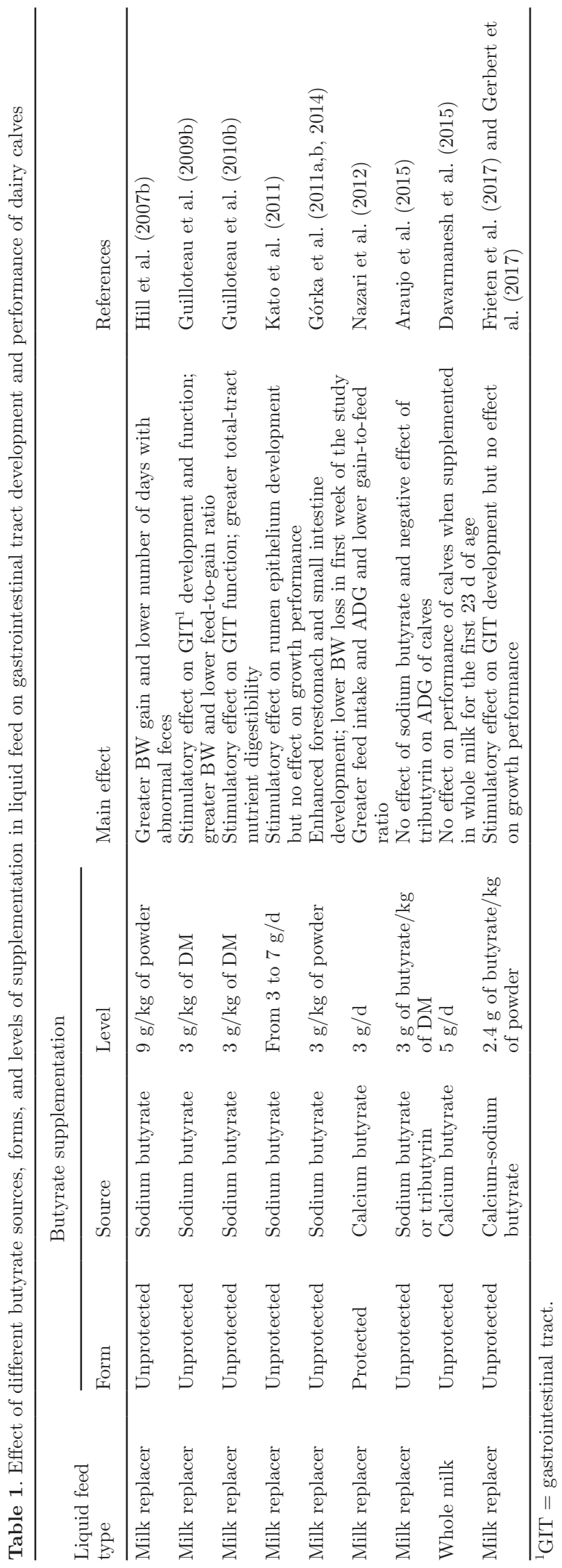




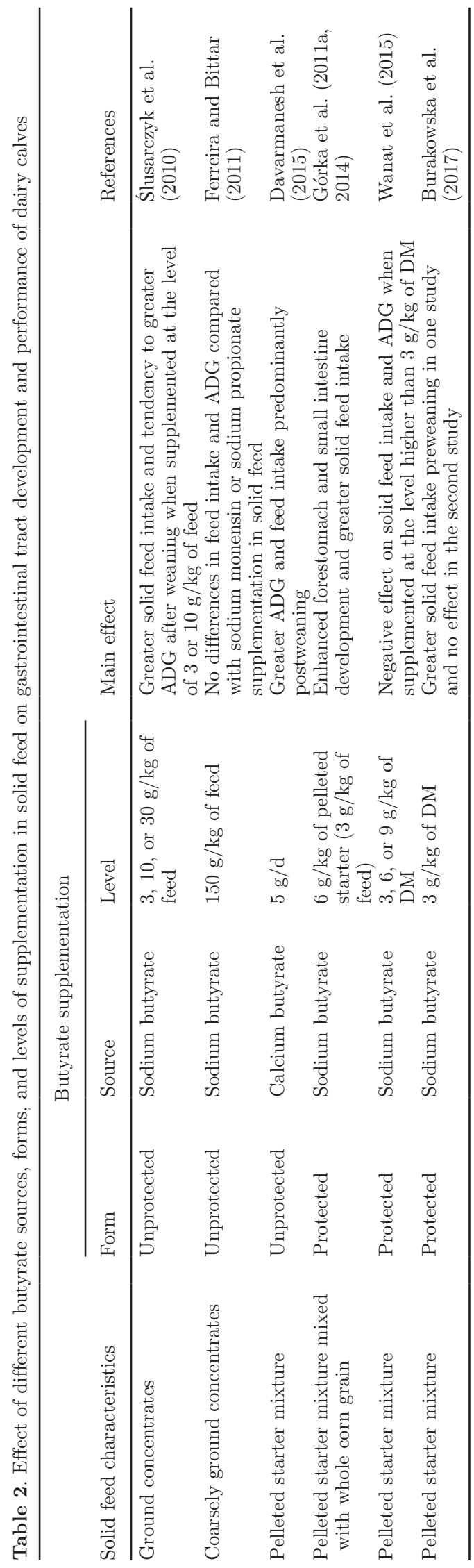

enhanced GIT development and increased solid feed intake during the preweaning period in calves (Górka et al., 2011a, 2014; Burakowska et al., 2017). A higher level of supplementation $(>0.3 \%$ of protected product in starter mixture), at least during preweaning, was shown to decrease starter intake and ADG of calves (Wanat et al., 2015). Similarly, very low levels of microencapsulated butyrate are sufficient to elicit a positive effect on GIT structure and function and growth performance in poultry (Moquet et al., 2016). Furthermore, a very narrow boundary between the dose of microencapsulated butyrate that results in a positive or negative effect was shown (Kaczmarek et al., 2016). Nevertheless, the currently recommended levels of protected butyrate use in solid feed for growing ruminants may be too low to exert a positive effect after weaning (Burakowska et al., 2017). A wide range of unprotected butyrate use in the literature makes it difficult to indicate the optimal level of supplementation. However, based on the available literature it seems that lower before weaning, and higher after weaning levels of supplementation in solid feed could be recommended, with protected butyrate being more effective preweaning and unprotected butyrate postweaning. Additional research is required in the future to determine the optimal dose of supplemental butyrate (in combination with its source and form) in solid feed for optimal outcomes for producers. Higher doses should also be justified economically.

\section{Potential Disadvantages of Supplementation}

Besides the advantages, the potential disadvantages of butyrate supplementation in solid feed for calves also need to be mentioned. Namely, the intensive ruminal epithelial cells proliferation and, particularly, differentiation and maturation may result in thickening of the stratum corneum, leading to rumen hyperkeratosis (Bull et al., 1965; McGavin and Morrill, 1976) and less efficient SCFA absorption (Bull et al., 1965). To support this, high molasses content in the starter mixture for calves (resulting in high butyrate concentration in the rumen) reduced starter mixture intake and negatively affected the performance of the animals, although longer rumen papillae in the calves fed the starter mixture with elevated molasses level were observed (Lesmeister and Heinrichs, 2005). Furthermore, when supplemented in a high-concentrate diet for growing lambs, butyrate reduced ex vivo butyrate absorption (Wilson et al., 2012). Those potential negative effects of dietary butyrate supplementation in solid feed for calves can be omitted by its short-term supplementation. Specifically, its supplementation in solid feed for calves for $4 \mathrm{~d}$ was sufficient to stimulate ruminal epithelium growth and reticulorumen tissue mass, without apparent thicken- 
ing of the stratum corneum (Figure 2). Furthermore, it has been shown that dietary butyrate supplementation results in lower cellulolytic and xylanolytic activity in the reticuloruminal digesta of growing sheep (Górka et al., 2017b), and butyrate infusion into the rumen reduced fiber digestion (Górka et al., 2017a). However, amylolytic activity in the reticulorumen was higher for sheep fed a diet with supplemental butyrate (Górka et al., 2017b) and (besides the negative effect on fiber digestion) ADG was increased. Taking into account current trends for feeding calves more liquid feeds for a longer period of time (e.g., 1,000 g of DM/d or more for a period of $8-10 \mathrm{wk}$ as opposed to $400-500 \mathrm{~g}$ for 4-6 wk) and feeding forage preweaning (Khan et al., 2016), the most effective form and source of butyrate supplementation in solid feed, depending on the liquid feed program (e.g., amount and type of liquid feed offered) and solid feed program (e.g., lack or presence of forage in the diet), may be an interesting subject for future studies.

It is possible to speculate that the specific taste or smell of butyrate may simply translate into lower

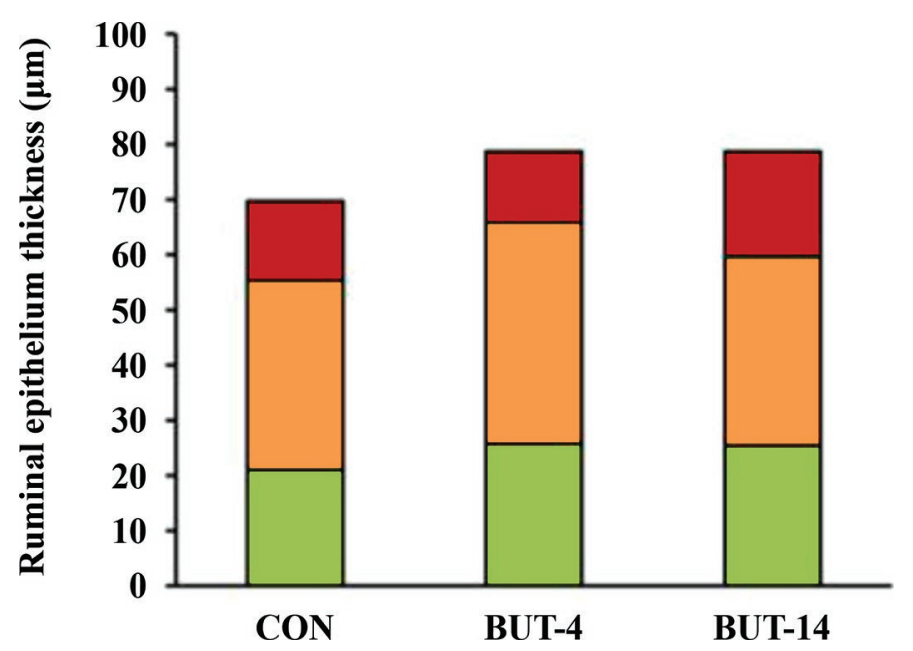

Figure 2. The effect of short-term sodium butyrate supplementation in pelleted starter mixture on ruminal epithelium thickness in the ventral sac of the rumen [P. Górka, P. Szarek (University of Agriculture in Krakow), J. Flaga (University of Agriculture in Krakow), M. Malkiewicz (University of Agriculture in Krakow), D. Wojtysiak (University of Agriculture in Krakow), M. M. Goldewski (Warsaw University of Life Sciences), and Z. M. Kowalski, unpublished]. The calves were fed pelleted starter mixture without sodium butyrate for $14 \mathrm{~d}(\mathrm{CON})$, pelleted starter mixture with sodium butyrate $(1.6 \%$ as fed) for $4 \mathrm{~d}$ and then CON for $10 \mathrm{~d}$ (BUT-4), or pelleted starter mixture with sodium butyrate for $14 \mathrm{~d}$ (BUT-14). The white (green) color refers to stratum basale, the gray (yellow) color to stratum granulosum and stratum spinosum, and the black (red) color to stratum corneum. Ruminal epithelium thickness was less for CON compared with BUT-4 and BUT-14 $(P=0.04)$, and stratum corneum was greater for BUT-14 compared with BUT-4 $(P<0.01)$. Color version available online. feed intake and lower ADG of calves observed in some studies, both when butyrate was supplemented in MR and in solid feed (Araujo et al., 2015; Wanat et al., 2015). However, in a palatability test sheep preferred hay treated with butyric acid (Gherardi and Black, 1991). It can be speculated that in the aforementioned studies a negative effect of butyrate on feed intake by calves could be rather the result of its systemic effect on the animal. For example, in a study of Araujo et al. (2015), butyrins were used as a source of butyrate. These were at least partially absorbed from the GIT as sn-2 monobutyrin (Moquet et al., 2016), and this molecule may have a systemic effect on the organism (Vinolo et al., 2012). The effect of different forms of butyrate on satiety signals seems to be an interesting direction for further studies. As a result, the unpleasant smell of butyrate seems to be more of a problem for humans than for animals. This potential disadvantage of butyrate supplementation can be reduced by the use of its protected forms. However, when used in a protected form, microcapsules of the protected product may separate from the liquid and float on the surface of the MR, affecting the active substance intake and efficiency of the feed additive. Protected forms of butyrate are also more expensive than nonprotected ones.

\section{CONCLUSIONS}

Dietary butyrate supplementation in both liquid feed and solid feed for calves can be considered as a means of promoting GIT development. Unprotected sodium butyrate supplementation in MR at a low level $(0.3 \%$ of DM) has been repeatedly shown to stimulate GIT development and the function and growth performance of preweaned calves, and can be recommended for practical use. On the other hand, whether inclusion of other sources or forms of butyrate in MR exerts a desired effect on GIT development of calves is currently unknown, although these (particularly protected forms of butyrate) are used in commercial MR. A comparison of the effects of different sources and forms of supplemental butyrate use in MR on the GIT development and performance of calves should be a subject of future works to confirm their effectiveness. Protected butyrate addition at a low level $(0.3 \%$ of protected product in DM) into solid feed has the potential to enhance GIT development of calves during the milk feeding period, but this effect may be not so apparent or even not in line with expectations postweaning. As a result, including protected forms of butyrate in solid feed for calves postweaning is not currently justified. As opposed to protected forms of butyrate, unprotected butyrate, particularly sodium butyrate supplementation in solid 
feed for calves, increased solid feed intake after weaning. As a result, the optimal form and source of supplemental butyrate may differ depending on the rearing stage (e.g., pre- and postweaning) and require further studies. It is also difficult to recommend optimal levels of unprotected butyrate supplementation in solid feed for calves due to the wide range of levels used in the published studies; however, a lower level of supplementation before weaning and a higher one after weaning seems to be a good starting point for further research. Knowledge on the effect of dietary butyrate supplementation on development of the omasum, abomasum, and large intestine still remains scarce, and the effect of its addition into WM on GIT development is lacking.

\section{ACKNOWLEDGMENTS}

Most of the research of P. Górka, Z. M. Kowalski, and R. Zabielski was funded by the Ministry of Science and Higher Education of Poland (Warsaw; grant no. 1164/P01/2006/31 and 3196/B/P01/35), whereas most of the studies of P. Guilloteau were funded by grants obtained within the frame of the Polonium Program ( $\mathrm{N}^{\circ}$ 13968PE), European Union project Feed for Pig Health (FOOD-CT-2004-506144) and Région Pays de la Loire (research project EPIMEMO), which are gratefully acknowledged.

\section{REFERENCES}

Anderson, K. L., T. G. Nagaraja, and J. L. Morrill. 1987. Ruminal metabolic development in calves weaned conventionally or early. J. Dairy Sci. 70:1000-1005. https://doi.org/10.3168/jds.S0022 $-0302(87) 80105-4$.

Andoh, A., T. Bamba, and M. Sasaki. 1999. Physiological and antiinflammatory roles of dietary fiber and butyrate in intestinal functions. J. Parenter. Enteral. Nutr. 23:S70-S73. https://doi.org/10 $.1177 / 014860719902300518$.

Araujo, G., M. Terré, A. Mereu, I. R. Ipharraguerre, and A. Bach. 2015. Effects of supplementing a milk replacer with sodium butyrate or tributyrin on performance and metabolism of Holstein calves. Anim. Prod. Sci. 56:1834-1841. https://doi.org/10.1071/ AN14930.

Ash, R., and G. D. Baird. 1973. Activation of volatile fatty acids in bovine liver and rumen epithelium. Biochem. J. 136:311-319. https://doi.org/10.1042/bj1360311.

Bailey, C. B. 1986. Growth of digestive organs and their contents in Holstein steers: Relation to body weight and diet. Can. J. Anim. Sci. 66:653-661. https://doi.org/10.4141/cjas86-072.

Baldwin, R. L., VI, K. R. McLeod, J. L. Klotz, and R. N. Heitmann. 2004. Rumen development, intestinal growth and hepatic metabolism in the pre- and postweaning ruminant. J. Dairy Sci. 87:E55E65. https://doi.org/10.3168/jds.S0022-0302(04)70061-2.

Bergman, E. N. 1990. Energy contributions of volatile fatty acids from the gastrointestinal tract in various species. Physiol. Rev. 70:567-590.

Biernat, M., R. Zabielski, P. Sysa, B. Sosak-Świderska, I. Le HuërouLuron, and P. Guilloteau. 1999. Small intestinal and pancreatic microstructures are modified by an intraduodenal CCK-A receptor antagonist administration in neonatal calves. Regul. Pept. 85:7785. https://doi.org/10.1016/S0167-0115(99)00079-8.
Bull, L. S., L. J. Bush, J. D. Friend, B. Harris Jr., and E. W. Jones. 1965. Incidence of ruminal parakeratosis in calves fed different rations and its relation to volatile fatty acid absorption. J. Dairy Sci. 48:1459-1466.

Burakowska, K., M. Przybyło, G. B. Penner, and P. Górka. 2017. Evaluating the effect of protein source and micro-encapsulated sodium butyrate in starter mixtures on gastrointestinal tract development of dairy calves. J. Dairy Sci. 100(Suppl. 2):347. (Abstr.)

Burrin, D. G., B. Stoll, and X. Guan. 2003. Glucagon-like peptide 2 function in domestic animals. Domest. Anim. Endocrinol. 24:103122. https://doi.org/10.1016/S0739-7240(02)00210-2.

Canani, R. B., M. Di Costanzo, L. Leone, M. Pedata, R. Meli, and A. Calignano. 2011. Potential beneficial effects of butyrate in intestinal and extraintestinal diseases. World J. Gastroenterol. 17:1519 1528. https://doi.org/10.3748/wjg.v17.i12.1519.

Cavini, S., S. Iraira, A. Siurana, A. Foskolos, A. Ferret, and S. Calsamiglia. 2015. Effect of sodium butyrate administered in the concentrate on rumen development and productive performance of lambs in intensive production system during the suckling and the fattening periods. Small Rumin. Res. 123:212-217. https://doi .org/10.1016/j.smallrumres.2014.11.009.

Chester-Jones, H., S. Moreland, D. Ziegler, M. Raeth-Knight, and J. van Eys. 2012. Pre- and postweaning performance and health of dairy calves when sodium butyrate is fed in milk replacer and/or calf starter during the summer months. J. Dairy Sci. 95(Suppl. 2):113.

Chilliard, Y., C. Martin, J. Rouel, and M. Doreau. 2009. Milk fatty acids in dairy cows fed whole crude linseed, extruded linseed, or linseed oil, and their relationship with methane output. J. Dairy Sci. 92:5199-5211. https://doi.org/10.3168/jds.2009-2375.

Claus, R., D. Günthner, and H. Letzgb. 2007. Effects of feeding fatcoated butyrate on mucosal morphology and function in the small intestine of the pig. J. Anim. Physiol. Anim. Nutr. (Berl.) 91:312318. https://doi.org/10.1111/j.1439-0396.2006.00655.x.

Connor, E. E., R. L. Baldwin IV, C. J. Li, R. W. Li, and H. Chung. 2013. Gene expression in bovine rumen epithelium during weaning identifies molecular regulators of rumen development and growth. Funct. Integr. Genomics 13:133-142. https://doi.org/10.1007/ s10142-012-0308-x.

Davarmanesh, A. R., M. H. Fathi Nasri, A. R. Kalantari Firouzabad, and M. B. Montazer-Torbati. 2015. Effect of Ca-butyrate and oleobiotec (a flavouring agent) supplemented starter on the performance of Holstein calves. J. Agric. Sci. 153:1506-1513. https://doi .org/10.1017/S0021859615000726.

Dengler, F., R. Rackwitz, F. Benesch, H. Pfannkuche, and G. Gäbel. 2015. Both butyrate incubation and hypoxia upregulate genes involved in the ruminal transport of SCFA and their metabolites. J. Anim. Physiol. Anim. Nutr. (Berl.) 99:379-390. https://doi.org/ 10.1111/jpn.12201.

Dieho, K., J. Dijkstra, J. T. Schonewille, and A. Bannink. 2016. Changes in ruminal volatile fatty acid production and absorption rate during the dry period and early lactation as affected by rate of increase of concentrate allowance. J. Dairy Sci. 99:5370-5384. https://doi.org/10.3168/jds.2015-10819.

Doreau, M., and Y. Chilliard. 1997. Digestion and metabolism of dietary fat in farm animals. Br. J. Nutr. 78(Suppl. 1):S15-S35. https://doi.org/10.1079/BJN19970132.

Drackley, J. K. 2008. Calf nutrition from birth to breeding. Vet. Clin. North Am. Food Anim. Pract. 24:55-86. https://doi.org/10.1016/ j.cvfa.2008.01.001.

Drucker, D. J. 2002. Gut adaptation and the glucagon-like peptides. Gut 50:428-435. https://doi.org/10.1136/gut.50.3.428.

Fernández-Rubio, C., C. Ordonez, J. Abad-González, A. GarciaGallego, M. Pilar Honrubia, J. Jose Mallo, and R. Balana-Fouce. 2009. Butyric acid-based feed additives help protect broiler chickens from Salmonella Enteritidis infection. Poult. Sci. 88:943-948. https://doi.org/10.3382/ps.2008-00484.

Ferreira, L. S., and C. M. Bittar. 2011. Performance and plasma metabolites of dairy calves fed starter containing sodium butyrate, calcium propionate or sodium monensin. Animal 5:239-245. https://doi.org/10.1017/S1751731110001965. 
Flaga, J., P. Górka, Z. M. Kowalski, U. Kaczor, P. Pietrzak, and R. Zabielski. 2011. Insulin-like growth factors 1 and 2 (IGF-1 and IGF-2) mRNA levels in relation to the gastrointestinal tract (GIT) development in newborn calves. Pol. J. Vet. Sci. 14:605-613. https://doi.org/10.2478/v10181-011-0090-Z.

Flaga, J., P. Górka, R. Zabielski, and Z. M. Kowalski. 2015. Differences in monocarboxylic acid transporter type 1 expression in rumen epithelium of newborn calves due to age and milk or milk replacer feeding. J. Anim. Physiol. Anim. Nutr. (Berl.) 99:521-530. https://doi.org/10.1111/jpn.12218.

Foote, A. P., C. M. Zarek, L. A. Kuehn, H. C. Cunningham, K. M. Cammack, H. C. Freetly, and A. K. Lindholm-Perry. 2017. Effect of abomasal butyrate infusion on gene expression in the duodenum of lambs. J. Anim. Sci. 95:1191-1196. https://doi.org/10.2527/jas .2016 .1022

Frieten, D., C. Gerbert, C. Koch, G. Dusel, K. Eder, E. Kanitz, J. M. Weitzel, and H. M. Hammon. 2017. Ad libitum milk replacer feeding, but not butyrate supplementation, affects growth performance as well as metabolic and endocrine traits in Holstein calves. J. Dairy Sci. 100:6648-6661. https://doi.org/10.3168/jds.2017-12722.

Galfi, P., and J. Bokori. 1990. Feeding trial in pigs with a diet containing sodium n-butyrate. Acta Vet. Hung. 38:3-17.

Gerbert, C., D. Frieten, C. Koch, G. Dusel, K. Eder, R. Zitnan, and H. Hammon. 2017. Organ and epithelial growth in the gastrointestinal tract of Holstein calves fed milk replacer ad libitum and supplemented with butyrate. Proc. Nutr. Physiol. 26:24.

Gherardi, S., and J. Black. 1991. Effect of palatability on voluntary feed intake by sheep. I. Identification of chemicals that alter the palatability of a forage. Aust. J. Agric. Res. 42:571-584. https:// doi.org/10.1071/AR9910571.

Górka, P., Z. M. Kowalski, P. Pietrzak, A. Kotunia, W. Jagusiak, J. J. Holst, R. Guilloteau, and R. Zabielski. 2011a. Effect of method of delivery of sodium butyrate on rumen development in newborn calves. J. Dairy Sci. 94:5578-5588. https://doi.org/10.3168/jds $.2011-4166$

Górka, P., Z. M. Kowalski, P. Pietrzak, A. Kotunia, W. Jagusiak, and R. Zabielski. 2011b. Is rumen development in newborn calves affected by different liquid feeds and small intestine development? J. Dairy Sci. 94:3002-3013. https://doi.org/10.3168/jds.2010-3499.

Górka, P., P. Pietrzak, A. Kotunia, R. Zabielski, and Z. M. Kowalski. 2014. Effect of method of delivery of sodium butyrate on maturation of the small intestine. J. Dairy Sci. 97:1026-1035. https://doi .org/10.3168/jds.2013-7251.

Górka, P., B. Śliwiński, J. Flaga, J. Wieczorek, M. M. Godlewski, E. Wierzchoś, R. Zabielski, and Z. M. Kowalski. 2017a. Effect of butyrate infusion into the rumen on butyrate flow to the duodenum, selected gene expression in the duodenum epithelium, and nutrient digestion in sheep. J. Anim. Sci. 95:2144-2155. https://doi.org/10 $.2527 /$ jas. 2016.1218 .

Górka, P., B. Śliwiński, R. Miltko, J. Flaga, J. Barć, M. M. Godlewski, R. Zabielski, and Z. M. Kowalski. 2017b. Effect of supplemental sodium butyrate on the activity of carbohydrate-digesting enzymes in the reticulo-ruminal digesta and brush border enzymes in sheep. J. Anim. Sci. 95(Suppl. 4):314.

Guilloteau, P., L. Martin, V. Eeckhaut, R. Ducatelle, R. Zabielski, and F. Van Immerseel. 2010a. From the gut to the peripheral tissues: the multiple effects of butyrate. Nutr. Res. Rev. 23:366-384. https://doi.org/10.1017/S0954422410000247.

Guilloteau, P., G. Savary, Y. Jaguelin-Peyrault, V. Rome, L. Le Normand, and R. Zabielski. 2010b. Dietary sodium butyrate supplementation increases digestibility and pancreatic secretion in young milk-fed calves. J. Dairy Sci. 93:5842-5850. https://doi.org/10 $.3168 /$ jds.2009-2751.

Guilloteau, P., R. Zabielski, and J. W. Blum. 2009a. Gastrointestinal tract and digestion in the young ruminant: Ontogenesis, adaptations, consequences and manipulations. J. Physiol. Pharmacol. 60(Suppl. 3):37-46.

Guilloteau, P., R. Zabielski, J. C. David, J. W. Blum, J. A. Morisset, M. Biernat, J. Woliński, D. Laubitz, and Y. Hamon. 2009b. Sodium-butyrate as a growth promoter in milk replacer formula for young calves. J. Dairy Sci. 92:1038-1049. https://doi.org/10 $.3168 /$ jds.2008-1213.

Harmon, D. L. 1986. Influence of dietary energy-intake and substrate addition on the in vitro metabolism of glucose and glutamine in rumen epithelial tissue. Comp. Biochem. Physiol. B Biochem. Mol. Biol. 85:643-647. https://doi.org/10.1016/0305-0491(86)90062-3.

Harmon, D. L., K. L. Gross, R. C. Krehbiel, K. K. Kreikemeier, M. L. Bauer, and R. A. Britton. 1991. Influence of dietary forage and energy intake on metabolism and acyl-CoA synthetase activity in bovine ruminal epithelial tissue. J. Anim. Sci. 69:4117-4127. https://doi.org/10.2527/1991.69104117x.

Heinrichs, J. 2005. Rumen development in the dairy calf. Adv. Dairy Technol. 17:179-187.

Herrick, K. J., A. R. Hippen, K. F. Kalscheur, D. J. Schingoethe, D. P. Casper, S. C. Moreland, and J. E. van Eys. 2017. Single-dose infusion of sodium butyrate, but not lactose, increases plasma betahydroxybutyrate and insulin in lactating dairy cows. J. Dairy Sci 100:757-768. https://doi.org/10.3168/jds.2016-11634.

Hill, T. M., J. M. Aldrich, R. L. Schlotterbeck, and H. G. Bateman II.. 2007a. Amino acids, fatty acids, and fat sources for calf milk replacers. Prof. Anim. Sci. 23:401-408. https://doi.org/10.15232/ S1080-7446(15)30995-5.

Hill, T. M., J. M. Aldrich, R. L. Schlotterbeck, and H. G. Bateman II.. 2007b. Effects of changing the fat and fatty acid composition of milk replacers fed to neonatal calves. Prof. Anim. Sci. 23:135-143. https://doi.org/10.15232/S1080-7446(15)30953-0.

Hill, T. M., H. G. Bateman II, J. M. Aldrich, and R. L. Schlotterbeck. 2010. Effect of milk replacer program on digestion of nutrients in dairy calves. J. Dairy Sci. 93:1105-1115. https://doi.org/10.3168/ jds.2009-2458

Hill, T. M., H. G. Bateman II, J. M. Aldrich, and R. L. Schlotterbeck. 2011a. Effect of various fatty acids on dairy calf performance. Prof. Anim. Sci. 27:167-175. https://doi.org/10.15232/ S1080-7446(15)30470-8.

Hill, T. M., J. D. Quigley, F. X. Suarez-Mena, H. G. Bateman II, and R. L. Schlotterbeck. 2016. Effect of milk replacer feeding rate and functional fatty acids on dairy calf performance and digestion of nutrients. J. Dairy Sci. 99:6352-6361. https://doi.org/10.3168/jds .2015-10812.

Hill, T. M., M. J. VandeHaar, L. M. Sordillo, D. R. Catherman, H G. Bateman II, and R. L. Schlotterbeck. 2011b. Fatty acid intake alters growth and immunity in milk-fed calves. J. Dairy Sci 94:3936-3948. https://doi.org/10.3168/jds.2010-3935.

Huhtanen, P., H. Miettinen, and M. Ylinen. 1993. Effect of increasing ruminal butyrate on milk yield and blood constituents in dairy cows fed a grass silage-based diet. J. Dairy Sci. 76:1114-1124. https://doi.org/10.3168/jds.S0022-0302(93)77440-8.

Kaczmarek, S. A., A. Barri, M. Hejdysz, and A. Rutkowski. 2016 Effect of different doses of coated butyric acid on growth performance and energy utilization in broilers. Poult. Sci. 95:851-859. https://doi.org/10.3382/ps/pev382.

Kato, S., K. Sato, H. Chida, S. G. Roh, S. Ohwada, S. Sato, P. Guilloteau, and K. Katoh. 2011. Effects of Na-butyrate supplementation in milk formula on plasma concentrations of GH and insulin, and on rumen papilla development in calves. J. Endocrinol. 211:241248. https://doi.org/10.1530/JOE-11-0299.

Kendall, P. E., and L. M. McLeay. 1996. Excitatory effects of volatile fatty acids on the in vitro motility of the rumen of sheep. Res. Vet. Sci. 61:1-6. https://doi.org/10.1016/S0034-5288(96)90101-0.

Khan, M. A., A. Bach, D. M. Weary, and M. A. G. von Keyserlingk. 2016. Invited review: Transitioning from milk to solid feed in dairy heifers. J. Dairy Sci. 99:885-902. https://doi.org/10.3168/jds.2015 $-9975$.

Klein, R. D., R. L. Kincaid, A. S. Hodgson, J. H. Harrison, J. K. Hillers, and J. D. Cronrath. 1987. Dietary fiber and early weaning on growth and rumen development of calves. J. Dairy Sci. 70:20952104. https://doi.org/10.3168/jds.S0022-0302(87)80259-X.

Konturek, S. J., R. Zabielski, J. W. Konturek, and J. Czarnecki. 2003. Neuroendocrinology of the pancreas; role of brain-gut axis in pancreatic secretion. Eur. J. Pharmacol. 481:1-14. https://doi.org/10 .1016/j.ejphar.2003.08.042. 
Kotunia, A., J. Woliński, D. Laubitz, M. Jurkowska, V. Romé, P. Guilloteau, and R. Zabielski. 2004. Effect of sodium butyrate on the small intestine development in neonatal piglets feed by artificial sow. J. Physiol. Pharmacol. 55(Suppl. 2):59-68.

Kowalski, Z. M., P. Górka, J. Flaga, A. Barteczko, K. Burakowska, J. Oprządek, and R. Zabielski. 2015. Effect of microencapsulated sodium butyrate in the close-up diet on performance of dairy cows in the early lactation period. J. Dairy Sci. 98:3284-3291. https:// doi.org/10.3168/jds.2014-8688.

Kristensen, N. B., and D. L. Harmon. 2004a. Effect of increasing ruminal butyrate absorption on splanchnic metabolism of volatile fatty acids absorbed from the washed reticulorumen of steers. J. Anim. Sci. 82:3549-3559. https://doi.org/10.2527/2004.82123549x.

Kristensen, N. B., and D. L. Harmon. 2004b. Splanchnic metabolism of volatile fatty acids absorbed from the washed reticulorumen of steers. J. Anim. Sci. 82:2033-2042. https://doi.org/10.2527/2004 $.8272033 \mathrm{x}$

Kristensen, N. B., S. G. Pierzynowski, and A. Danfaer. 2000a. Net portal appearance of volatile fatty acids in sheep intraruminally infused with mixtures of acetate, propionate, isobutyrate, butyrate, and valerate. J. Anim. Sci. 78:1372-1379. https://doi.org/10 $.2527 / 2000.7851372 \mathrm{x}$.

Kristensen, N. B., S. G. Pierzynowski, and A. Danfaer. 2000b. Portal-drained visceral metabolism of 3-hydroxybutyrate in sheep. J. Anim. Sci. 78:2223-2228. https://doi.org/10.2527/2000.7882223x.

Krokowicz, L., B. F. Kaczmarek, P. Krokowicz, Z. Stojcev, J. Mackiewicz, J. Walkowiak, M. Drews, and T. Banasiewicz. 2014. Sodium butyrate and short chain fatty acids in prevention of travellers' diarrhoea: A randomized prospective study. Travel Med. Infect. Dis. 12:183-188. https://doi.org/10.1016/j.tmaid.2013.08.008.

Le Gall, M., M. Gallois, B. Seve, I. Louveau, J. J. Holst, I. P. Oswald, J. P. Lallès, and P. Guilloteau. 2009. Comparative effect of orally administered sodium butyrate before or after weaning on growth and several indices of gastrointestinal biology of piglets. Br. J. Nutr. 102:1285-1296. https://doi.org/10.1017/S0007114509990213.

Lesmeister, K. E., and A. J. Heinrichs. 2005. Effects of adding extra molasses to a texturized calf starter on rumen development, growth characteristics, and blood parameters in neonatal dairy calves. J. Dairy Sci. 88:411-418. https://doi.org/10.3168/jds S0022-0302(05)72702-8.

Li, R. W., S. T. Wu, R. L. Baldwin, W. Z. Li, and C. J. Li. 2012a. Perturbation dynamics of the rumen microbiota in response to exogenous butyrate. PLoS One 7:e29392. https://doi.org/10.1371/ journal.pone.0029392.

Li, S., E. Khafipour, D. O. Krause, A. Kroeker, J. C. RodriguezLecompte, G. N. Gozho, and J. C. Plaizier. 2012b. Effects of subacute ruminal acidosis challenges on fermentation and endotoxins in the rumen and hindgut of dairy cows. J. Dairy Sci. 95:294-303. https://doi.org/10.3168/jds.2011-4447.

Malhi, M., H. Gui, L. Yao, J. R. Aschenbach, G. Gäbel, and Z. Shen. 2013. Increased papillae growth and enhanced short-chain fatty acid absroption in the rumen of goats are associated with transient increases in cyclin D1 expression after ruminal butyrate infusion. J. Dairy Sci. 96:7603-7616. https://doi.org/10.3168/jds.2013-6700.

Mallo, J. J., A. Balfagón, M. I. Gracia, P. Honrubia, and M. Puyalto. 2012. Evaluation of different protections of butyric acid aiming for release in the last part of the gastrointestinal tract of piglets. J. Anim. Sci. 90(Suppl. 4):227-229. https://doi.org/10.2527/jas .53959 .

Manzanilla, E. G., M. Nofrarias, M. Anguita, M. Castillo, J. F. Perez, S. M. Martin-Orue, C. Kamel, and J. Gasa. 2006. Effects of butyrate, avilamycin, and a plant extract combination on the intestinal equilibrium of early-weaned pigs. J. Anim. Sci. 84:2743-2751. https://doi.org/10.2527/jas.2005-509.

Mazzoni, M., M. Le Gall, S. De Filippi, L. Minieri, P. Trevisi, J. Woliński, G. Lalatta-Costerbosa, J. P. Lallés, P. Guilloteau, and P. Bosi. 2008. Supplemental sodium butyrate stimulates different gastric cells in weaned pigs. J. Nutr. 138:1426-1431.

McGavin, M. D., and J. L. Morrill. 1976. Scanning electron microscopy of ruminal papillae in calves fed various amounts and forms of roughage. Am. J. Vet. Res. 37:497-508.
Mentschel, J., R. Leiser, C. Mülling, C. Pfarrer, and R. Claus. 2001. Butyric acid stimulates rumen mucosa development in the calf mainly by a reduction of apoptosis. Arch. Anim. Nutr. 55:85-102. https://doi.org/10.1080/17450390109386185.

Moquet, P. C. A., L. Onrust, F. van Immerseel, R. Ducatelle, W. H. Hendriks, and R. P. Kwakkel. 2016. Importance of release location on the mode of action of butyrate derivatives in the avian gastrointestinal tract. Worlds Poult. Sci. J. 72:61-80. https://doi.org/10 $.1017 / \mathrm{s} 004393391500269 x$.

Nazari, M., K. Karkoodi, and A. Alizadeh. 2012. Performance and physiological responses of milk-fed calves to coated calcium butyrate supplementation. S. Afr. J. Anim. Sci. 42:296-303. https://doi .org/10.4314/sajas.v42i3.12.

Palmquist, D. L., A. Denise Beaulieu, and D. M. Barbano. 1993. Feed and animal factors influencing milk fat composition. J. Dairy Sci 76:1753-1771. https://doi.org/10.3168/jds.S0022-0302(93)77508 $-6$.

Penner, G. B., M. A. Steele, J. R. Aschenbach, and B. W. McBride. 2011. Ruminant Nutrition Symposium: Molecular adaptation of ruminal epithelia to highly fermentable diets. J. Anim. Sci. 89:1108-1119. https://doi.org/10.2527/jas.2010-3378.

Piva, A., V. Pizzamiglio, M. Morlacchini, M. Tedeschi, and G. Piva. 2007. Lipid microencapsulation allows slow release of organic acids and natural identical flavors along the swine intestine. J. Anim. Sci. 85:486-493. https://doi.org/10.2527/jas.2006-323.

Ploger, S., F. Stumpff, G. B. Penner, J. D. Schulzke, G. Gäbel, H. Martens, Z. M. Shen, D. Gunzel, and J. R. Aschenbach. 2012. Microbial butyrate and its role for barrier function in the gastrointestinal tract. Pages 52-59 in Ann. N. Y. Acad. Sci. Vol. 1258. M. Fromm and J. D. Schulzke, ed. Blackwell Science Publ, Oxford, UK. https://doi.org/10.1111/j.1749-6632.2012.06553.x.

Quigley, J. D. III, P. Smith, and R. N. Heitmann. 1991. Changes in plasma volatile fatty acids in response to weaning and feed intake in young calves. J. Dairy Sci. 74:258-263. https://doi.org/10.3168/ jds.S0022-0302(91)78168-X.

Rossi, F., M. Maurizio, M. Francesco, C. Giovanna, and P. Gianfranco. 2003. Rumen degradation and intestinal digestibility of rumen protected amino acids: comparison between in situ and in vitro data. Anim. Feed Sci. Technol. 108:223-229. https://doi.org/10.1016/ S0377-8401(03)00131-7.

Sakata, T., and H. Tamate. 1978. Rumen epithelial cell proliferation accelerated by rapid increase in intaruiminal butyrate. J. Dairy Sci. 61:1109-1113. https://doi.org/10.3168/jds.S0022-0302(78)83694 -7 .

Seegraber, F. J., and J. L. Morrill. 1986. Effect of protein source in calf milk replacers on morphology and absorptive ability of small intestine. J. Dairy Sci. 69:460-469. https://doi.org/10.3168/jds.S0022 $-0302(86) 80424-6$

Serbester, U., C. Cakmakci, S. Goncu, and M. Gorgulu. 2014. Effect of feeding starter containing butyrate salt on pre- and post-weaning performance of early or normally weaned calves. Rev. Med. Vet. 165:44-48.

Shen, Z., S. Kuhla, R. Zitnan, H. M. Seyfert, F. Schneider, H. Hagemeister, A. Chudy, B. Löhrke, J. W. Blum, H. Hammon, and J. Voigt. 2005. Intraruminal infusion of n-butyric acid induces an increase of ruminal papillae size independent of IGF-1 system in castrated bulls. Arch. Anim. Nutr. 59:213-225. https://doi.org/10 $.1080 / 17450390500216894$.

Shen, Z., H. Martens, and M. Schweigel-Rontghen. 2012. Na transport across rumen epithelium of hay-fed sheep is acutely stimulated by the peptide IGF-1 in vitro. Exp. Physiol. 97:497-505. https://doi .org/10.1113/expphysiol.2011.061580.

Ślusarczyk, K., J. A. Strzetelski, and I. Furgał-Dierżuk. 2010. The effect of sodium butyrate on calf growth and serum level of betahydroxybutyric acid. J. Anim. Feed Sci. 19:348-357. https://doi .org/10.22358/jafs/66298/2010.

Steele, M. A., L. Dionissopoulos, O. AlZahal, J. Doelman, and B. W. McBride. 2012. Rumen epithelial adaptation to ruminal acidosis in lactating cattle involves the coordinated expression of insulin-like growth factor-binding proteins and a cholesterolgenic enzyme. J. Dairy Sci. 95:318-327. https://doi.org/10.3168/jds.2011-4465. 
Storm, A. C., M. D. Hanigan, and N. B. Kristensen. 2011. Effects of ruminal ammonia and butyrate concentrations on reticuloruminal epithelial blood flow and volatile fatty acid absorption kinetics under washed reticulorumen conditions in lactating dairy cows. J. Dairy Sci. 94:3980-3994. https://doi.org/10.3168/jds.2010-4091.

Vazquez-Anon, M., A. J. Heinrichs, J. M. Aldrich, and G. A. Varga. 1993. Postweaning age effects on rumen fermentation endproducts and digesta kinetics in calves weaned at 5 weeks of age. J. Dairy Sci. 76:2742-2748. https://doi.org/10.3168/jds.S0022 -0302(93)77611-0.

Vinolo, M. A. R., H. G. Rodrigues, W. T. Festuccia, A. R. Crisma V. S. Alves, A. R. Martins, C. L. Amaral, J. Fiamoncini, S. M. Hirabara, F. T. Sato, R. A. Fock, G. Malheiros, M. F. dos Santos, and R. Curi. 2012. Tributyrin attenuates obesity-associated inflammation and insulin resistance in high-fat-fed mice. Am. J. Physiol. Endocrinol. Metab. 303:E272-E282. https://doi.org/10 .1152 /ajpendo.00053.2012

Wanat, P., P. Górka, and Z. M. Kowalski. 2015. Short communication: Effect of inclusion rate of microencapsulated sodium butyrate in starter mixture for dairy calves. J. Dairy Sci. 98:2682-2686. https://doi.org/10.3168/jds.2014-8482.

Weigand, E., J. W. Young, and A. D. McGilliard. 1972. Extent of butyrate metabolism by bovine ruminoreticulum epithelium and relationship to absorption rate. J. Dairy Sci. 55:589-597. https:// doi.org/10.3168/jds.S0022-0302(72)85541-3.

Wiese, B. I., P. Górka, T. Mutsvangwa, E. Okine, and G. B. Penner. 2013. Short communication: Interrelationship between butyrate and glucose supply on butyrate and glucose oxidation by ruminal epithelial preparations. J. Dairy Sci. 96:5914-5918. https://doi .org/10.3168/jds.2013-6677.

Wilson, D. J., T. Mutsvangwa, and G. B. Penner. 2012. Supplemental butyrate does not enhance the absorptive or barrier functions of the isolated ovine ruminal epithelia. J. Anim. Sci. 90:3153-3161. https://doi.org/10.2527/jas.2011-4315.

Wu, S. H. W., and A. Papas. 1997. Rumen-stable delivery systems. Adv. Drug Deliv. Rev. 28:323-334. https://doi.org/10.1016/S0169 $-409 \mathrm{X}(97) 00087-2$.

Zabielski, R. 1998. Regulatory peptides in milk, food and in the gastrointestinal lumen of young animals and children. J. Anim. Feed Sci. 7:65-78. https://doi.org/10.22358/jafs/69956/1998.

Zabielski, R., I. Le Huërou-Luron, and P. Guilloteau. 1999. Development of gastrointestinal and pancreatic functions in mammalians (mainly bovine and porcine species): Influence of age and ingested food. Reprod. Nutr. Dev. 39:5-26. https://doi.org/10.1051/rnd: 19990101.

Zabielski, R., J. Morisset, P. Podgurniak, V. Romé, M. Biernat, C. Bernard, J. A. Chayvialle, and P. Guilloteau. 2002. Bovine pancreatic secretion in the first week of life: Potential involvement of intestinal CCK receptors. Regul. Pept. 103:93-104. https://doi .org/10.1016/S0167-0115(01)00362-7.

Zabielski, R., T. Onaga, H. Mineo, S. G. Pierzynowski, and S. Kato. 1994. Local versus peripheral blood administration of cholecystokinin- 8 and secretin on pancreatic secretion in calves. Exp. Physiol. 79:301-311. 